\title{
Inmigración y distribución de la población anciana en España (2002-2011): una aproximación desde la escala municipal
}

\section{Inmigration and distribution of the elderly population in Spain (2002-2011): an approach from the local level}

\author{
Alejandro López González ${ }^{1}$ y José Antonio Aldrey Vázquez²
}

\section{INMIGRACIÓN Y ENVEJECIMIENTO DEMOGRÁFICO}

El efecto de la inmigración sobre el crecimiento demográfico español en los últimos años es evidente. Entre los censos de 2001 y 2011 prácticamente dos tercios de la variación de la población ha recaído sobre los extranjeros, lo que es muy relevante si ciframos ese crecimiento en casi 6 millones de personas. Teniendo en cuenta que una parte sustancial de la inmigración más reciente es motivada por la búsqueda de empleo, creemos que tan abultada inmigración ha incidido en la moderación del envejecimiento de la población española desde un punto de vista relativo, porque los valores numéricos de la población mayor no han dejado de crecer en este decenio.

El envejecimiento es un reto para las sociedades desarrolladas de difícil respuesta, y es frecuente pensar en la inmigración como una solución dado su carácter selectivo en términos de edad. G. de la Dehesa (2008) opina que la afirmación precedente es cierta en el corto plazo, al predominar entre ellos

\footnotetext{
${ }^{1}$ Profesor Titular de Geografía Humana en el Departamento de Geografía de la Universidad de León: alejandro.lopez@unileon.es

2 Profesor Titular de Análisis Geográfico Regional en la Universidad de Santiago de Compostela: joseantonio.aldrey@usc.es
} 
edades más jóvenes que las de la población de acogida y tasas de fecundidad más elevadas. Sin embargo, cree que a medio y largo plazo perdería validez por el propio envejecimiento de los inmigrantes, la convergencia de las tasas de fecundidad con las de la población local, y por la limitada capacidad social y política de las sociedades receptoras para absorber los flujos de inmigrantes precisos para garantizar su efecto prolongado sobre el envejecimiento. Esta tesis es avalada también por otros investigadores (López de Lera, 2006; Oso Casas, 2006; Garrido Medina, 2005; Delgado y Zamora, 2004). Por su parte, J. Arango (2004) discrepa basándose en trabajos sobre países de prolongada tradición inmigratoria, pues es escéptico sobre la efectividad de la inmigración como motor de un rejuvenecimiento efectivo de la población, aunque entiende que sí puede ralentizar el proceso de envejecimiento, apreciación en la que coinciden T. Castro (2010) y los estudios realizados por la división de población de Naciones Unidas (2001). A este respecto, el estudio de Naciones Unidas estima necesarios flujos inmigratorios sustancialmente mayores a los actuales para contrarrestar el proceso de envejecimiento de los países industrializados. A esta tesis dirigida a relativizar el papel de la inmigración sobre las dinámicas demográficas subyacentes contribuyen, por una parte J. R. Valero (2009), con un análisis para el conjunto del Estado y, por otra, A. Cabré y A. Domingo (2007), para Cataluña. En ambas aportaciones se destaca el papel complementario, no sustitutivo, de los inmigrantes en relación a la población autóctona.

Esta perspectiva parece confirmarse repasando estudios sectoriales, que resaltan los efectos beneficiosos a corto plazo, posiblemente acrecentados por el estado actual de la inmigración en España: inmigración muy reciente en proceso de asentamiento, no registrándose en toda su amplitud los efectos más beneficiosos de la reunificación familiar (Villena y Gómez, 2006; Martínez y Villares, 2006); si bien señalan algunas sombras sobre sus consecuencias a largo plazo. En el plano económico, impulsan el crecimiento atenuando el envejecimiento demográfico de la población autóctona (Conde-Ruiz, García y Navarro, 2008; Antuñano, Ochando y Soler, 2009; López Trigal, 2010), aunque para ser sostenible se precisaría que la entrada de inmigrantes se prolongase en el tiempo. En el plano social, más concretamente en lo relativo a las pensiones, hay un consenso en que es beneficioso a corto y medio plazo debido a que los inmigrantes son cotizantes netos, si bien con un horizonte temporal mayor incrementará la presión sobre el fondo de cobertura de las pensiones al hacerse efectivo el derecho de los inmigrantes a percibir las mismas (Conde-Ruiz, Jimeno y Valera, 2006; Jiménez-Ridruejo, 2008; JiménezRidruejo y Borondo, 2009), sobre el sistema sanitario (Jansà, 2006), o sobre 
los servicios de prestación de asistencia a las personas mayores (Martínez Buján, 2005; Rodríguez Rodríguez, 2012).

En resumen, la inmigración, a pesar de las dudas sobre su repercusión a medio y largo plazo, es una variable favorable en la reducción del envejecimiento y, en consecuencia, posee repercusiones socioeconómicas beneficiosas. En este artículo mediremos su aportación a la estructura demográfica y a la distribución de la población vieja en España, mediante el empleo de indicadores sobre participación de la inmigración en la variación del colectivo de ancianos, herramienta aplicada a diferentes ámbitos territoriales homogéneos. Estos indicadores no van más allá del corto plazo, todo lo más podrían aventurarse algunos efectos en el medio plazo. Esta escasa capacidad de predicción no sólo es atribuible al método empleado, sino también a la difícil coyuntura económica inaugurada en 2007 que introduce incertidumbre en cualquier previsión a largo plazo, pues es la demanda de mano de obra el motor de la inmigración (Arango, 2004).

El presente trabajo ha sido estructurado en tres apartados, el primero define aspectos metodológicos, en el que diseñamos, en primer lugar, un indicador para la medición de la participación de la inmigración en la variación del grupo de ancianos; en segundo lugar, pretendemos disociar en este proceso el comportamiento de los principales grupos nacionales, dado que existen diferencias notables en este fenómeno entre los distintos orígenes geográficos de nuestros inmigrantes (Aldrey, González y Santos, 2008). El segundo consiste en el análisis de los resultados obtenidos de aplicar dicho indicador a distintas escalas, basándonos en agregados territoriales de municipios delimitados a partir de la combinación de ciertos rasgos. Finalmente, el tercer apartado se apoya en la constatación de la existencia de colectivos de inmigrantes que escapan a motivaciones laborales y en él pretendemos testear las diferencias de los grandes grupos nacionales en relación con su participación en la variación del grupo de ancianos.

\section{Metodología}

\section{Fuente}

La fuente empleada para la incidencia de la inmigración sobre el envejecimiento en el corto y medio plazo será el Padrón Municipal de Habitantes, que nos da una fiabilidad aceptable, aunque aquejado de problemas en la contabilización de los inmigrantes en lo relacionado con su permanencia en los mu- 
nicipios en los que están inscritos, lo que lleva a errores de sobreestimación en el caso de la inmigración internacional laboral (De Castro, 2004; Garrido, 2004; Devolder, Gil y Forte, 2009). Del mismo modo, se ha constatado un subregistro endémico en el caso de la inmigración internacional de jubilados, que se ha dirigido en su inmensa mayoría hacia las áreas turísticas españolas, que cuentan con niveles muy bajos de empadronamiento (Casado y Rodríguez, 2002; Carvajal y Navarro, 2011).

Por otro lado, no es infrecuente que cambien de residencia (los inmigrantes de carácter laboral) y no lo notifiquen, en especial si el movimiento se produce fuera de las fronteras estatales, de manera que los registros padronales pueden contabilizar extranjeros que realmente ya no residen en ese municipio y ni tan siquiera en España (Recaño y Domingo, 2005). El proceso para depurar los padrones es largo y costoso, ya que se completa después de varios trámites administrativos. De todos modos, el propio INE ha reconocido que esta es una merma pequeña de fiabilidad, sobre todo cuanto más nos alejemos de la escala local. Por lo demás, se trata de una fuente fiable para el cómputo de los extranjeros que llegan por motivos laborales, dada la necesidad de contar con un lugar de residencia (una dirección concreta en un municipio concreto) para el acceso a la sanidad y educación y, por el momento, sin complicaciones policiales en cuanto a su control, aunque esa fiabilidad se reduce considerablemente cuando los inmigrantes no requieren de estos servicios y pueden tener acceso a la sanidad de manera gratuita o mediante la provisión privada, como sucede con buena parte de los jubilados de procedencia europea.

\section{Datos}

La información extraída de la explotación del Padrón se ha compilado a escala municipal, lo que implica un total 8.074 registros en 2002, 8.111 en 2007 y 8.116 en 2011. Las diferencias observadas se deben a la creación de nuevos municipios, pero también a la presencia de un numeroso colectivo de territorios de los que en 2002 el INE no ofreció dato alguno. Se han construido tres series temporales (2002, 2007 y 2011), permitiendo analizar los cambios experimentados por la población anciana extranjera en dos etapas sucesivas pero de carácter contrapuesto: la primera, entre 2002 y 2007 caracterizada por un fuerte crecimiento económico amparado en la promoción inmobiliaria, que demanda mucha mano de obra barata (en gran medida procedente del exterior) y en parte dirigida a potenciales clientes que entran dentro de lo que se denomina «turismo residencial» o «inmigración residencial»; la segunda 
etapa, 2007-2011, presenta características radicalmente diferentes, el pinchazo de la burbuja inmobiliaria implica un elevado desempleo, y si bien parece que los flujos inmigratorios no han cesado aún, éstos se han atenuado y se han desencadenado emigraciones de retorno.

Los datos tomados del padrón y empleados en este trabajo son los siguientes:

1. Población española y extranjera, discriminando entre el montante total y el colectivo de los ancianos. Consideramos como tales a aquellos individuos de 65 y más años. Este umbral es la edad legal de jubilación, no la efectiva que como valor medio es menor (ver Casado y Rodríguez, 2002), y la utilizamos debido a la dificultad de encontrar un límite de edad inferior en el que coincida tanto la jubilación efectiva de la población española como la correspondiente a otros países de donde proceden los inmigrantes de mayor edad.

2. Población inmigrante de los principales colectivos foráneos. A pesar de la heterogeneidad de la población extranjera, en 2011 cuatro de cada diez inmigrantes procede de Ecuador, Marruecos, Rumanía y Reino Unido. Se han seleccionado no sólo por su propio peso específico, sino también por el distinto impacto que han tenido sobre la estructura demográfica del conjunto de la población española: los tres primeros son poblaciones que alimentaron la demanda de mano de obra a lo largo de buena parte de la década de 2000, demográficamente dominados por población joven en edad de trabajar. Por el contrario, los británicos constituyen un colectivo atraído por el clima español, muchos de ellos ancianos.

La escala empleada para la explotación de los datos ha sido la municipal, aunque la excesiva fragmentación del mapa local español ha aconsejado agruparlos en conjuntos con características, en principio, comunes. Con este objetivo combinamos tres criterios básicos:

a) Pertenencia a una de las siete áreas metropolitanas (Nel.lo, 2007), no contempladas legalmente pero si extrapolables a partir de otro tipo de fuentes.

b) Tamaño de la población. Tomando como referente la media aritmética entre las poblaciones de cada municipio para el período 2002-2011, se han estructurado los municipios no metropolitanos en tres niveles: espacios rurales con menos de 10.000 habitantes, pequeñas ciudades de 10.000 a 49.999 , y ciudades medias con 50.000 y más habitantes.

c) Carácter litoral o interior. Aplicado a los municipios menores de 50.000 habitantes. 
Este triple criterio nos permite estructurar los municipios españoles en ocho grupos (cuadro 1):

\section{CUAdro 1}

\section{GRUPOS DE MUNICIPIOS}

\section{Grupos de municipios}

\begin{tabular}{llr}
\hline 01 & Municipios metropolitanos & 390 \\
02 & Ciudades medias & 87 \\
03 & Ciudades pequeñas del litoral mediterráneo, andaluz y archipiélagos & 120 \\
$03 n$ & Ciudades pequeñas del litoral gallego y cantábrico & 48 \\
04 & Ciudades pequeñas interiores & 271 \\
05 & $\begin{array}{l}\text { Municipios semirrurales y rurales del litoral mediterráneo, andaluz y } \\
\text { archipiélagos }\end{array}$ & 122 \\
$05 n$ & Municipios semirrurales y rurales del litoral gallego y cantábrico & 103 \\
06 & Municipios semirruales y rurales interiores & 6.975 \\
\hline
\end{tabular}

Fuente: Elaboración propia.

a) Los municipios metropolitanos son 390 , pertenecientes a los siete conjuntos metropolitanos definidos por O. Nel.lo (2007): Barcelona -164 municipios-, Bilbao -35-, Madrid -62-, Málaga -13-, Sevilla -46-, Valencia -44- y Zaragoza -26-. Para la delimitación exacta de las distintas áreas metropolitanas, ante la ausencia de un reconocimiento de esta figura jurídica, nos basamos en los documentos de ordenación territorial y en la literatura científica (vid. para Barcelona el Plan Territorial General de Cataluña, 1995; para Bilbao el Plan Territorial Parcial del Bilbao Metropolitano, 2006; para Madrid García Ballesteros, A. y Sainz Berzal, B., 2002; para Málaga y Sevilla planes subregionales de ordenación del territorio elaborados por la Junta de Andalucía en 2006 y 2009; para Valencia delimitación propuesta en 2001 para la Entidad Pública de Transporte Metropolitano; y para Zaragoza López, Á. y otros, 2002).

b) Ciudades medias. Suman 87 municipios y forman un compendio de territorios no metropolitanos con población media superior a 50.000 habitantes. En este caso consideramos indiferente la ubicación litoral o interior, al primar el carácter urbano sobre cualquier otro condicionante. 
c) Ciudades pequeñas. Con población media entre 10.000 y 50.000 habitantes, constituyen un colectivo que hemos subdividido entre aquellas de carácter litoral y las situadas en el interior. Las primeras suman 168 municipios, a su vez repartidos entre 120 en el litoral mediterráneo, andaluz y archipiélagos, y 48 en la costa del norte peninsular. En el interior de la península este grupo lo constituyen 271 territorios.

d) Espacios rurales. Municipios con población media inferior a 10.000 habitantes, que suponen prácticamente nueve de cada diez unidades administrativas de este nivel. En el litoral se incluyen 225 municipios (122 en el mediterráneo, andaluz y archipiélagos; 103 en el norte peninsular); mientras que en el interior son 6.975.

\section{Mediciones de la contribución de los inmigrantes al colectivo de ancianos}

La medida de la contribución de los extranjeros a la variación del grupo etario de ancianos de la población se articula a través de dos indicadores. Primero se cuantifica la contribución real de los extranjeros al incremento de población mayor en cada tipo de espacio mediante la siguiente fórmula (ecuación 1):

$$
\varphi_{v i}=\frac{V X_{i, t+1}-V X_{i, t}}{V_{i, t+1}-V_{i, t}}=\frac{\Delta V X_{i}}{\Delta V_{i}}
$$

Donde $\varphi_{v}$ mide la participación de los extranjeros sobre la variación del número de ancianos, VX representa genéricamente al número de ancianos extranjeros, $\mathrm{V}$ el total de ancianos, el subíndice i se refiere genéricamente a la unidad espacial a que se aplica, y t y $\mathrm{t}+\mathrm{l}$ denotan el momento inicial y final de cada intervalo de tiempo. Los resultados se refieren a las dos etapas ya mencionadas, 2002-2007 y 2008-2011.

Los cálculos anteriores están diseñados para resaltar la participación de los extranjeros sobre el stock total de ancianos, extranjeros y nativos. Los resultados obtenidos se han reducido a un intervalo que va de 0 a 1: 0 representa una ausencia total en la contribución de los inmigrantes a la variación del número de ancianos, y 1 implica una participación total de los extranjeros en esa aportación al grupo de mayor edad. Dado que las operaciones algebraicas resultantes de aplicar la ecuación 1 da resultados diferentes a los mencionados, hemos recurrido a un convenio por el cual a los valores negativos los hacemos equivaler a cero y a los superiores a 1 los asimilamos a esta cifra. 
En el cálculo del índice nos encontramos con dificultades de carácter algebraico que obligaron a adoptar criterios puramente matemáticos y no fácilmente subsanables atendiendo a técnicas de estandarización estadística. Estas dificultades encuentran su origen en que comparamos variaciones de magnitudes absolutas y se sustancian en dos situaciones bastante generalizadas: un primer grupo de distorsiones viene derivada de la presencia de decrementos (valores con signo negativo) bien en el numerador, bien en el denominador; el segundo estriba en variaciones exageradamente fuertes del número de ancianos extranjeros, muy superior a la del total de ancianos. En ambos casos, no existe una contribución por parte de los extranjeros al crecimiento del número de personas de la tercera edad fácilmente mensurable. En estos casos optamos por adjudicarles variables dicotómicas: damos el valor uno en aquellos casos en los que se corrobore que la totalidad del crecimiento de colectivo de mayor edad se apoya sobre los extranjeros (variaciones positivas en el numerador y negativas en el denominador, crecimiento del número de ancianos extranjeros muy por encima del crecimiento de ancianos totales), o bien en aquellos otros en los que no existe contribución de ningún tipo pues conviven retrocesos del número de ancianos extranjeros con crecimiento del número total de mayores de 65 años.

Complementariamente hemos ajustado los datos originales empleando medias ponderadas, multiplicando las series de población anciana extranjera y total por el cociente entre los efectivos totales de cada municipio y la desviación típica; los resultados obtenidos no permiten sustanciales mejoras, aunque si ofrecen una visión ajustada de los valores obtenidos para cada agrupación de municipios al tener en cuenta las diferencias asociadas a la talla demográfica de cada municipio.

La razón de este procedimiento estriba en la intención de medir la participación de los extranjeros en el proceso de envejecimiento de la población, mensurabilidad sujeta a un intervalo cerrado.

\section{Correlación entre los principales grupos de inmigrantes y el incremento del número de ancianos}

A diferencia del conjunto de inmigrantes, nuestro conocimiento es parco en relación a la estructura de edades por nacionalidades. Únicamente contamos con una nutrida literatura que aporta indicios sobre la estructura por edades de cada grupo (Copete y Sempere, 2009; García y Palacios, 2009; Pajares Alonso, 2009), desconociendo el aporte real de cada nacionalidad al colectivo 
de ancianos extranjeros. Partimos de la hipótesis de la existencia de diferencias sustanciales en la génesis del proceso migratorio para dos grupos diferenciados: los oriundos de países ricos llegan a España por motivos en gran medida de disfrute de ocio y de tiempo libre, contribuyendo al envejecimiento de la población (Janoschka y Haas, 2013; Benson y O'Reilly, 2009); mientras los procedentes de países menos desarrollados llegan atraídos por oportunidades laborales, rejuveneciendo al conjunto del colectivo demográfico. Una suposición más de partida, esta en términos geográficos, alude a la existencia de sensibles diferencias entre la distribución espacial: los primeros, en función de sus objetivos migratorios, se asientan en aquellos territorios en los que el clima se ajusta mejor a sus demandas (litoral mediterráneo, andaluz y archipiélagos); los segundos se acomodan a las ofertas laborales, implicando una mayor dispersión geográfica, si bien esta circunstancia no excluye concentraciones en áreas de mayor dinamismo (espacios metropolitanos y ciudades medias, principalmente).

Las estadísticas del INE a escala municipal no recogen a todas las nacionalidades, únicamente las consideradas más significativas, si bien, según se ha ido haciendo más heterogéneo el origen inmigratorio, se ha ampliado el número de ellas. En nuestro caso hemos seleccionado las más significativas en número de efectivos, que además son representativas de ámbitos geográficos muy diferentes.

Recurrimos al índice de correlación de Pearson, medición adecuada en el caso de variables numéricas para comparar los montantes municipales, por una parte, del total de ancianos extranjeros y, de otra, de cada una de las nacionalidades señaladas. Dadas las sustanciales diferencias cuantitativas entre los volúmenes correspondientes a los distintos municipios españoles hemos optado por transformar en logaritmos naturales las variables sometidas al análisis de correlación, suavizando las distorsiones derivadas de las grandes diferencias en tamaño entre los municipios españoles. Como es sabido, el coeficiente de Pearson mide el grado de dependencia entre variables, obteniendo un rango de resultados dentro del intervalo [-1,1], marcando sus extremos una relación de dependencia perfecta (negativa y positiva), mientras

\footnotetext{
${ }^{3}$ En 2002 las nacionalidades sobre las que informaba el Padrón a nivel municipal eran Alemania, Reino Unido, Marruecos, Colombia y Ecuador. En 2007 se añadieron Bulgaria, Francia, Italia, Rumania, Rusia, Ucrania, Argentina, Bolivia, Perú y China. En 2011 a las anteriores se unieron Polonia, Portugal, Argelia, Nigeria, Senegal, Brasil, Chile, Cuba, Paraguay, República Dominicana, Uruguay, Venezuela y Pakistán.
} 
que cero refleja independencia entre las variables sometidas a comparación. El índice de Pearson se mide a partir de una formula bien conocida (ecuación 2):

$$
\rho_{\lambda_{v} \lambda_{\alpha}}=\frac{\sigma_{\lambda_{v} \lambda_{\alpha}}}{\sigma_{\lambda_{v}} \sigma_{\lambda_{\alpha \alpha}}}
$$

Donde $\rho_{\lambda v \lambda \alpha}$ es el índice de correlación de Pearson, $\lambda_{v}$ es el logaritmo natural de la población anciana extranjera, $\lambda_{\alpha}$ el logaritmo natural de la población extranjera de cualquiera de las nacionalidades estudiadas (británicos, rumanos, ecuatorianos y marroquíes), $\sigma_{\lambda v \lambda \alpha}$ la covarianza, y $\sigma_{\lambda v}$ y $\sigma_{\lambda \alpha}$ las desviaciones típicas correspondientes a las variables incluidas en el modelo.

LA APORTACIÓN DE LOS INMIGRANTES AL COLECTIVO DE ANCIANOS EN EL PERÍOdO 2002-2011

\section{Inmigración y ancianos: los grandes grupos}

El cuadro 2 recoge las variaciones experimentadas por los stocks de población anciana y total, tanto para el conjunto español como de los grupos de municipios, recogiendo los lapsos temporales 2002-2007 y 2008-2011, amén de la conjunción de ambos períodos. Acompañando las cifras absolutas incluimos los valores del indicador que mide la contribución de los extranjeros a dichas variaciones.

Sobre los extranjeros recae el peso del crecimiento de la población española en el pasado decenio, aunque participando muy poco en la variación de la población anciana: siete de cada diez nuevos residentes en territorio español son inmigrantes, si bien entre 2002 y 2007 éstos prácticamente llegaron a ser ocho de cada diez, y en el periodo subsiguiente retrocedieron hasta seis de cada diez, síntoma evidente de cambio en el contexto económico; en cambio, sólo dos de cada diez ancianos son extranjeros, detectándose incluso una reducción en la participación de los mismos sobre el proceso de incremento de la población de mayor edad entre el primer período y el segundo. Dicho de otra manera, han compensado en parte el envejecimiento de la población autóctona, con lo que podemos concluir en el neto predominio de una inmigración laboral, por lo menos si nos quedamos con España en su conjunto.

Pero esta visión general encubre profundas diferencias a una escala más detallada. En los municipios netamente urbanos la participación de los extranjeros en el crecimiento de la población total es notable en el primer período, 
CuAdro 2

FLUJOS DE VARIACIÓN DE POBLACIÓN TOTAL Y ANCIANA POR GRUPOS DE MUNICIPIOS, CONTRIBUCIÓN DE LOS INMIGRANTES

\begin{tabular}{|c|c|c|c|c|c|c|c|c|c|}
\hline $\begin{array}{l}2002- \\
2007\end{array}$ & G. 1 & G. 2 & G. 3 & G. $3 n$ & G. 4 & G. 5 & G. $5 n$ & G. 6 & Total \\
\hline$\Delta P_{v x}$ & 15.800 & 20.990 & 26.931 & 441 & 6.339 & 7.563 & 130 & 13.786 & 91.980 \\
\hline$\Delta P_{v}$ & 143.456 & 117.990 & 55.603 & 10.373 & 29.745 & 13.085 & 2.126 & (29.616) & 342.762 \\
\hline$\varphi$ & 0,110 & 0,178 & 0,484 & 0,043 & 0,213 & 0,578 & 0,061 & 1,000 & 0,268 \\
\hline$\varphi_{\sigma}$ & 0,220 & 0,510 & 0,856 & 0,033 & 0,345 & 0,906 & 0,059 & 0,381 & 0,338 \\
\hline$\Delta P_{x}$ & 1.006 .565 & 583.224 & 277.062 & 15.296 & 253.448 & 56.338 & 5.906 & 340.160 & 2.537 .999 \\
\hline$\Delta P$ & 1.193 .138 & 700.975 & 436.432 & 65.229 & 376.505 & 88.650 & 1.779 & 432.357 & 3.295 .065 \\
\hline$\lambda$ & 0,844 & 0,832 & 0,635 & 234 & 0,673 & 0,636 & 3,320 & 0,787 & 0,770 \\
\hline$\lambda_{\sigma}$ & 1,602 & ,792 & 0,740 & 127 & 0,465 & 0,766 & 0,211 & 0,391 & 1,301 \\
\hline $\begin{array}{l}2008- \\
2011\end{array}$ & G. 1 & G. 2 & G. 3 & G. 3n & G. 4 & G. 5 & G. $5 n$ & G. 6 & Total \\
\hline$\Delta P_{v x}$ & $J$ & 2 & 30 & 422 & 39 & 8.370 & 207 & 17.127 & 105.767 \\
\hline$\Delta P_{v}$ & 223.215 & 165.608 & 64.113 & 13.628 & 55.844 & 14.897 & 4.754 & 42.892 & 584.951 \\
\hline $\begin{array}{l}\varphi \\
\varphi_{\sigma}\end{array}$ & $\begin{array}{l}0,067 \\
0,112\end{array}$ & $\begin{array}{l}0,162 \\
0,474\end{array}$ & & & & & & $\begin{array}{l}0,399 \\
0,396\end{array}$ & $\begin{array}{l}0,181 \\
0,225\end{array}$ \\
\hline$\Delta P_{x}$ & 422.179 & 277.258 & 139.233 & 11.122 & 138244 & 27.995 & 5.373 & 214.563 & 1.235 .967 \\
\hline$\Delta P$ & 745.819 & 378.011 & 228.072 & 34.275 & 258.506 & 46.109 & 3.704 & 379.001 & 2.073 .497 \\
\hline $\begin{array}{l}\lambda \\
\lambda_{\sigma}\end{array}$ & $\begin{array}{l}0,566 \\
0,691\end{array}$ & $\begin{array}{l}0,733 \\
0,643\end{array}$ & $\begin{array}{l}0,610 \\
0,734\end{array}$ & $\begin{array}{l}0,324 \\
0,189\end{array}$ & $\begin{array}{l}0,535 \\
0,272\end{array}$ & $\begin{array}{l}0,607 \\
0,624\end{array}$ & $\begin{array}{l}1,451 \\
0,261\end{array}$ & $\begin{array}{l}0,566 \\
0,302\end{array}$ & $\begin{array}{l}0,596 \\
0,663\end{array}$ \\
\hline $\begin{array}{l}2002- \\
2011\end{array}$ & G. 1 & G. 2 & G. 3 & G. 3n & G. 4 & G. 5 & G. $5 n$ & G. 6 & Total \\
\hline$\Delta P_{v x}$ & 30.715 & 47.283 & 57.035 & 863 & 14.128 & 15.933 & 337 & 30.913 & 197.747 \\
\hline$\Delta P_{v}$ & 366.671 & 283.598 & 119.716 & 24.001 & 85.589 & 27.982 & 6.880 & 13.276 & 927.713 \\
\hline $\begin{array}{c}\varphi \\
\varphi_{\sigma}\end{array}$ & $\begin{array}{l}0,084 \\
0,211\end{array}$ & $\begin{array}{l}0,167 \\
0,486\end{array}$ & $\begin{array}{l}0,476 \\
0,861\end{array}$ & $\begin{array}{l}0,036 \\
0,032\end{array}$ & $\begin{array}{l}0,165 \\
0,655\end{array}$ & $\begin{array}{l}0,569 \\
0,909\end{array}$ & $\begin{array}{l}0,049 \\
0,045\end{array}$ & $\begin{array}{l}2,328 \\
0,511\end{array}$ & $\begin{array}{l}0,213 \\
0,270\end{array}$ \\
\hline$\Delta P_{x}$ & 1.428 .744 & 860.482 & 416.295 & 26.418 & 391.692 & 84.333 & 11.729 & 554.723 & 3.773 .966 \\
\hline$\Delta P$ & 1.938 .957 & 1.078 .986 & 664.504 & 99.504 & 635.011 & 134.759 & 5.483 & 811.358 & 5.368 .562 \\
\hline $\begin{array}{l}\lambda \\
\lambda\end{array}$ & $\begin{array}{l}0,737 \\
1,197\end{array}$ & $\begin{array}{l}0,797 \\
0,743\end{array}$ & $\begin{array}{l}0,626 \\
0,727\end{array}$ & $\begin{array}{l}0,265 \\
0,146\end{array}$ & $\begin{array}{l}0,617 \\
0,581\end{array}$ & $\begin{array}{l}0,626 \\
0,723\end{array}$ & $\begin{array}{l}2,139 \\
0,230\end{array}$ & $\begin{array}{l}0,684 \\
0,371\end{array}$ & $\begin{array}{l}0,703 \\
1,058\end{array}$ \\
\hline
\end{tabular}

Fuente: Elaboración propia a partir de la explotación del padrón municipal de habitantes (INE).

Nota: $\varphi$ es la contribución de los extranjeros a la variación al grupo de edad de 65 y más años y $\varphi_{\sigma}$ el mismo indicador ajustado a la desviación estándar intragrupo; $\lambda$ es la contribución de los extranjeros a la variación de la población total y $\lambda_{\sigma}$ idéntico indicador ajustado a la desviación estándar. 
con ocho de cada diez nuevos censados, en cambio es donde la participación sobre el envejecimiento es menor. Estos primeros datos atestiguan que los inmigrantes que llegan lo hacen buscando trabajo; esta apreciación se confirma desde el inicio de la crisis, de 2008 en adelante, cuando los inmigrantes ya representan poco más de la mitad del crecimiento total en las áreas metropolitanas, mientras en las ciudades medias cae hasta poco más de siete de cada diez nuevos empadronados; del mismo modo retrocede aún más su participación sobre la variación de ancianos, si bien en esta magnitud influye el fuerte crecimiento del número de mayores nativos en este período.

Las pequeñas ciudades (grupos 3, 3n y 4) no constituyen un agregado de comportamiento coherente. Los grupos 3 y 4 presentan una capacidad de atracción de inmigrantes que, sin ser tan grande como en los municipios urbanos de superior tamaño, si es relevante: seis de cada diez nuevos vecinos lo son de otras nacionalidades, retrocediendo algo en los dos periodos estudiados, en especial en el grupo 4. En el grupo 3n la participación de la inmigración extranjera es minoritaria, consecuente con el menor dinamismo económico ofrecido por las pequeñas ciudades costeras del norte, aunque creciente debido a la menor vinculación con el sector inmobiliario. En lo tocante a la contribución de los extranjeros al grupo de ancianos encontramos tres escenarios distintos: entre 2002 y 2007 el grupo 3 mostraba una participación de la inmigración muy alta sobre ese grupo etario $(0,484)$, que se mantiene con pocas variaciones en el quinquenio siguiente $(0,470)$ y sin apenas modificaciones en términos absolutos; en el grupo 3n, la contribución al incremento de los mayores por parte de los inmigrantes es anecdótica; el grupo 4 se mantiene en línea con la de los grupos 1 y $2(0,213)$ en los años de fuerte crecimiento, retrocediendo drásticamente en la etapa de crisis ulterior. Estos tres escenarios ilustran tres contextos dispares: el grupo 3, dominado por el turismo de sol y playa, es receptor de inmigración residencial consolidada y relativamente aislada de las dificultades que acompañan al inmigrante laboral cuando la creación de empleo desfallece; el grupo 4 incluye muchos municipios en la vecindad de áreas urbanas, o que se constituyen por sí mismos en focos de actividad económica, atrae a bastantes migrantes laborales; el grupo 3n permanece prácticamente al margen de los flujos migratorios, limitándose los extranjeros a una presencia casi testimonial

En lo que atañe a los municipios más pequeños (grupos $5,5 \mathrm{n}$ y 6 ) muestran, igualmente, tres situaciones diferentes. El grupo 5 muestra unas cifras parejas a la del grupo 3, incluso con una mayor participación sobre el aumento del grupo de ancianos de los inmigrantes $(0,562$ y 0,569$)$, que nos remite a varios matices: primero, la inmigración es netamente de jubilados; 
segundo, el menor tamaño implica menor dinamismo endógeno y, en consecuencia, menor atracción hacia colectivos inmigrantes por motivo de trabajo; tercero, las cifras absolutas muestran que en el segundo lustro, marcado por el desempleo, la inmigración crece, por tanto la inmigración laboral es secundaria frente a la residencial de comportamiento inelástico ante la oferta de empleo. El grupo 5n abarca a un colectivo poco representativo, tal y como muestran los valores absolutos, y registra rasgos similares a los del grupo 1: el crecimiento recae exclusivamente sobre los inmigrantes, aunque su participación sobre el incremento de ancianos es prácticamente nula $(0,061$ y 0,049$)$; la inmigración es, por tanto laboral, decayendo el flujo de nuevos inmigrantes en términos absolutos entre un quinquenio y el siguiente. En el grupo 6 el grueso del crecimiento demográfico correspondió a la inmigración, si bien con un peso menguante, tanto en números absolutos como relativos: entre 2002 y 2007 el peso de la inmigración sobre el crecimiento total se situaba en cifras superiores incluso a los valores nacionales $(0,787$ frente a 0,770$)$, en el quinquenio siguiente esta participación retrocede $(0,566)$. Más compleja es la contribución al grupo de población de mayor edad, interfiriendo el comportamiento anómalo de la población anciana autóctona: entre 2002 y 2007 la variación de ancianos fue globalmente negativa, contrastando el retroceso de este grupo entre los nacionales frente a un crecimiento entre los extranjeros; en el quinquenio 2008-2011 la situación se normaliza, el incremento del número de ancianos es generalizado a todos los colectivos, representando una porción apreciable los extranjeros sobre esta variación $(0,399)$, contribución en la que puede participar turismo residencial o inmigración de retorno.

\section{Análisis a escala municipal}

Siguiendo con el análisis de la contribución de los extranjeros a la variación del grupo de personas de mayor edad y descendiendo a una escala municipal (figuras 1 y 2, cuadro 3) se pueden apuntar algunas cuestiones. Utilizando tres intervalos para medir la fuerza de esa contribución (leve con valor máximo de 0,33; moderada desde ese índice hasta 0,66; e, intensa si supera el valor de 0,66$)$, podemos observar en primer lugar que, en el caso de las áreas metropolitanas, los foráneos extranjeros contribuyen de una manera notable al envejecimiento en esos ámbitos territoriales en los dos períodos estudiados (cuadro 3 y figura 2).

Así, en 2002-2007 casi dos tercios de los municipios metropolitanos conocieron una aportación moderada o intensa al crecimiento del grupo etario de 
CUAdRo 3

APORTACIÓN DE LOS EXTRANJEROS AL ENVEJECIMIENTO A NIVEL MUNICIPAL (\%)

\begin{tabular}{|c|c|c|c|}
\hline Grupo & Aportación & $2002-2007$ & $2008-2011$ \\
\hline \multirow{3}{*}{ Grupo 1} & Leve & 36,7 & 44,0 \\
\hline & Moderada & 20,9 & 21,6 \\
\hline & Intensa & 42,4 & 34,4 \\
\hline \multirow{3}{*}{ Grupo 2} & Leve & 48,3 & 50,6 \\
\hline & Moderada & 17,2 & 17,2 \\
\hline & Intensa & 34,5 & 32,2 \\
\hline \multirow{3}{*}{ Grupo 3} & Leve & 13,3 & 6,7 \\
\hline & Moderada & 4,2 & 5,0 \\
\hline & Intensa & 82.5 & 88,3 \\
\hline \multirow{3}{*}{ Grupo 3n } & Leve & 56,2 & 62,5 \\
\hline & Moderada & 37,5 & 33,3 \\
\hline & Intensa & 6,3 & 4,2 \\
\hline \multirow{3}{*}{ Grupo 4} & Leve & 53,3 & 52,6 \\
\hline & Moderada & 23,0 & 23,0 \\
\hline & Intensa & 23,7 & 24,4 \\
\hline \multirow{3}{*}{ Grupo 5} & Leve & 9,1 & 9,1 \\
\hline & Moderada & 9,1 & 7,4 \\
\hline & Intensa & 81,8 & 83,5 \\
\hline \multirow{3}{*}{ Grupo 5n } & Leve & 80,2 & 74,3 \\
\hline & Moderada & 8,9 & 13,8 \\
\hline & Intensa & 10,9 & 11,9 \\
\hline \multirow{3}{*}{ Grupo 6} & Leve & 78,3 & 73,7 \\
\hline & Moderada & 6,2 & 7,1 \\
\hline & Intensa & 15,5 & 19,2 \\
\hline
\end{tabular}

Fuente: Elaboración propia. 
mayores de 65 años desde su colectivo de extranjeros, frente a algo más de un tercio donde fue de escasa entidad. En el período siguiente, 2008-2011, su incidencia en el proceso de incremento en las cohortes senectas ha seguido siendo notable en la mayor parte de los casos. Sin embargo, la evolución muestra un mayor peso de los que presentan escasa repercusión en el incremento del número de ancianos. Por su parte, las capitales de las áreas metropolitanas no tienen un comportamiento uniforme, ya que en 2002-2007 en tres de ellas el aporte al incremento de los mayores desde el colectivo de extranjeros fue leve (Bilbao, Málaga y Sevilla), frente a las otras cuatro en las que se mostró moderada. Sin embargo, en el período más reciente (2008-2011) la situación se invierte, siendo cinco las capitales metropolitanas con una aportación poco significativa al grupo situado en la cima de la pirámide demográfica, frente a dos en las que es moderada (Madrid y Málaga). Vemos, por tanto, como en una primera aproximación de conjunto, la tendencia ha sido a que en el período más reciente la contribución de los extranjeros al incremento de ancianos se haya reducido sensiblemente en las áreas metropolitanas, tanto en el número total de municipios como en las propias capitales, entre las que son mayoría aquellas que sus residentes foráneos tienen una incidencia escasa en el incremento de la senectud global de sus poblaciones. Parece, por tanto, que la crisis económica está favoreciendo una menor incidencia a la hora de nutrir los grupos de población de mayor edad por la aportación de los foráneos en las áreas metropolitanas.

Si nos fijamos en cada una de esas áreas metropolitanas más en detalle podemos comprobar cómo las diferencias son notables entre unas y otras. Así, en el caso de la de Bilbao tienen un peso abrumador los municipios en los que el aporte de los foráneos al grupo de mayores es muy leve, incrementándose incluso entre ambos períodos (pasando de un 85 a un 91\%). Por su parte, en el área metropolitana zaragozana el aporte se mostró leve también en el primer período (cerca del $60 \%$ de los municipios; frente a un $24 \%$ con aportación moderada y un $20 \%$ intensa), para incrementarse de manera considerable en 2008-2011, cuando el aporte intenso y moderado alcanzó casi al 70\% de los municipios. Sin duda nos hayamos, en el caso de estas dos grandes áreas urbanas, ante una situación en la que el incremento del aporte a los grupos de mayor senectud se produce por la sustancial caída en los nuevos suministros de inmigrantes, produciendo una mayor edad media de los existentes.

El área metropolitana de Madrid presenta un comportamiento diferente, pues son una gran mayoría los municipios en los que sus extranjeros inciden mucho en el incremento global de los ancianos, con una aportación intensa entre 2002 y 2007 en tres cuartas partes de ellos, rozando la misma el 80\% entre 2008-2011. 
En el caso de los entornos de la capital del Estado las mayores intensidades en la incidencia positiva en el incremento de la senectud aparecen en una orla de municipios inmediata a ella, decayendo cuanto más nos alejamos de la urbe central (en la que el aporte es moderado).

El desigual comportamiento de estas grandes áreas urbanas se aprecia bien en la divergencia observada en la comparación entre Madrid y Barcelona, donde la tendencia ha sido inversa, apareciendo una menor incidencia en el crecimiento del número de ancianos desde el colectivo de los extranjeros en el segundo período estudiado. Así, en 2002-2007 en el área metropolitana catalana tienen una incidencia leve casi la mitad de los municipios, englobando territorialmente a una compacta franja costera al norte, centro y sur de Barcelona (exceptuando la capital y algunos municipios inmediatos), así como en un amplio sector interior en el centro del área metropolitana, al norte y oeste de la capital. En esa misma fecha tuvieron un comportamiento moderado muchos municipios del área inmediata a la Ciudad Condal. En el siguiente período crece de manera espectacular el grupo de municipios con una aportación leve, englobando a más del 45\%, reduciéndose fuertemente los que presentaban con anterioridad una aportación intensa.

En el caso valenciano ha ocurrido lo mismo, con una tendencia al crecimiento de los municipios con una aportación leve al aumento del grupo de los mayores que se ha incrementado de manera notable entre los dos períodos (del 43 al 59\%), fundamentalmente los inmediatos a la capital del Turia.

Por su parte, en las áreas metropolitanas andaluzas el comportamiento tampoco es uniforme. En Sevilla el primer período contaba con una muy notable significación de los municipios con aportación escasa al número de ancianos por parte de sus foráneos (tres de cada cinco), que englobaban gran parte del área urbana hispalense. La significación del aporte escaso se vio reducida en el segundo período, englobando a la mitad de los territorios, hecho que se acompañó de un notable crecimiento de las entidades municipales que presentan mayor aportación para nutrir a los grupos de población más senecta (un tercio del total).

Finalmente, Málaga es la aglomeración urbana con mayores diferencias con respecto al resto, pues en ella la intensidad del aporte al envejecimiento de los extranjeros es sumamente notable (por encima del 92\% en 2002-2007 y del 84\% en 2008-2011), escapando en el primero de esos intervalos sólo Málaga capital a esa categoría, mientras que en el segundo se le añadió el municipio de Totalán. La explicación es fácil y evidente. Estamos en la Costa del Sol, lugar elegido por decenas de miles de ancianos europeos como lugar de residencia buscando las benignidades climáticas del entorno. 


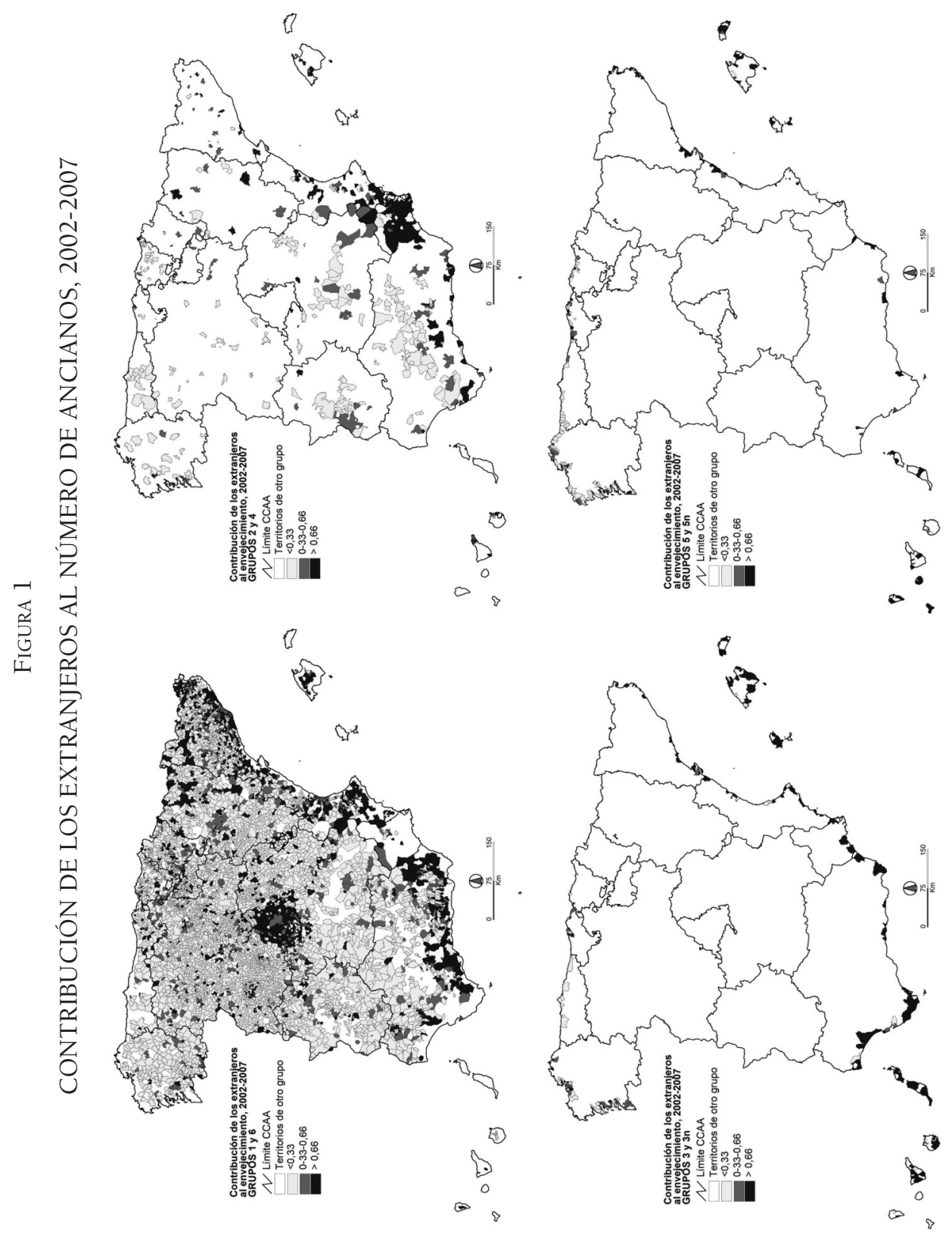



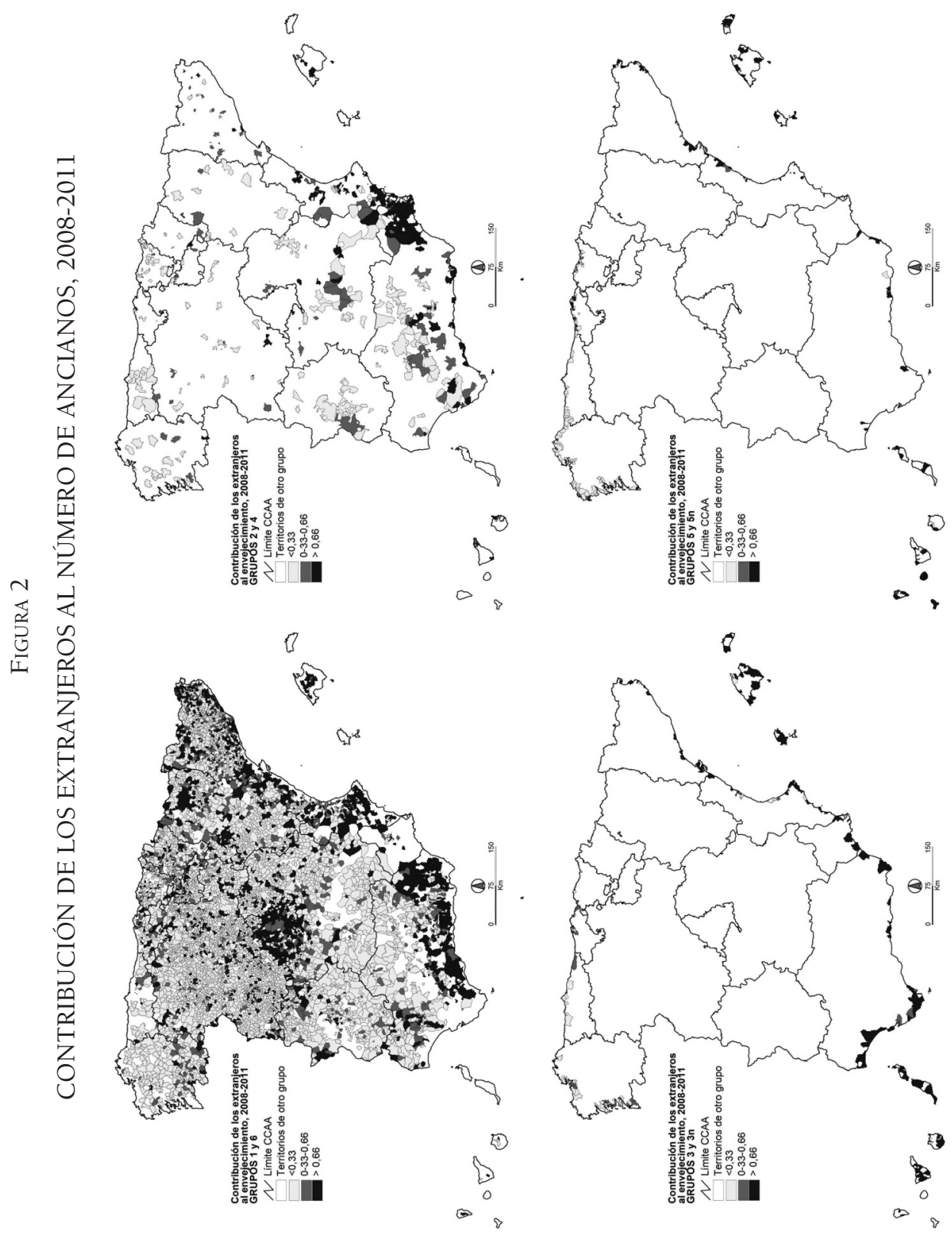

Estudios Geográficos, Vol. LXXV, 277, pp. 619-648, julio-diciembre 2014

ISSN: 0014-1496, eISSN: 1988-8546, doi: 10.3989/estgeogr.201420 
En el caso de los municipios semirrurales y rurales interiores (grupo 6) la tónica general en ambos períodos es la escasa incidencia que tiene la aportación de los inmigrantes para incrementar cohortes de mayor edad, repartiéndose de una manera muy regular a lo largo de toda la geografía estatal con excepción de los más próximos a la costa en el área sur (Andalucía), levantina (Cataluña, Comunidad Valencia y Murcia) y en ambos archipiélagos, donde los fenómenos de instalación de extranjeros de edad avanzada con motivaciones climáticas dejan sentir su influencia. Además, son también menos significativos los municipios con aporte leve en los entornos inmediatos de las áreas metropolitanas. La evolución reciente, 2008-2011 (figura 2, cuadro 3), ha supuesto un descenso en el peso relativo de este tipo de municipios con influencia escasa en el acrecentamiento del grupo de edades avanzadas, con una distribución sin apenas cambios dignos de mención. Han crecido, sin embargo, los otros dos supuestos, estando los que poseen una mayor incidencia situados en la orla exterior contigua a los límites de las áreas metropolitanas de Madrid, Málaga, Barcelona y Valencia, así como en las áreas próximas al litoral sur, al Mediterráneo y en los archipiélagos balear y canario.

Por lo que respecta a las ciudades medias (grupo 2), el comportamiento ha sido inverso al recién apuntado, pues entre los dos intervalos temporales se ha producido un leve incremento de los municipios que presentan un aporte leve. El reparto territorial muestra una concentración de los de aportación leve en las ciudades medias del interior peninsular, pues en general escapan a esta tónica las del levante, Cataluña, Baleares, Canarias, Valencia y Andalucía. Este incremento se produce por una menor significación de los municipios con una incidencia intensa en el incremento del número de ancianos. Sin embargo, el montante de territorios con aportación moderada se ha mantenido inalterado entre ambos períodos.

En el caso de las ciudades pequeñas del interior (grupo 4) el montante de municipios englobado en cada uno de los tres índices se ha mantenido estable. Aquellos con aportes poco importantes al incremento del grupo de mayores tienen una especial implantación en la mitad occidental estatal, con una mayor importancia entre los del norte (Galicia, Asturias, Cantabria y País Vasco), aunque también son notables en Castilla-La Mancha, Extremadura, norte de Andalucía y Castilla y León. Con todo, los que tienen una incidencia moderada o intensa cuentan con mayor notoriedad en las áreas próximas a la costa levantina, andaluza y catalana, con pocos ejemplos en el interior.

Si nos fijamos en las ciudades pequeñas del litoral mediterráneo, andaluz y archipiélagos (grupo 3), la situación apunta hacia un aporte general e intenso al aumento de los mayores por parte de los colectivos de inmigrantes extranjeros, 
que además tiende a incrementarse, aunque no de forma muy acusada (figura 2 y cuadro 3). Estamos ante el litoral donde la inmigración de carácter climático es la tónica característica. Este fenómeno no aparece en las ciudades pequeñas del litoral gallego y cantábrico (grupo 3n), con una mayoría de municipios con una contribución de sus foráneos bastante exigua al grupo de ancianos entre 2002-2007, incrementándose en el lapso temporal más reciente. Este tipo de situación se presenta en todos los casos asturianos y del País Vasco, mientras que los de fuerza moderada tienen un mayor peso en Galicia y oriente de Cantabria.

Por su parte, en los municipios semirrurales y rurales del litoral mediterráneo, andaluz y archipiélagos (grupo 5), vuelven a dominar los que tienen cifras muy altas en la aportación al crecimiento del grupo de mayor senectud, dejándose notar la incidencia del asentamiento de extranjeros europeos de elevada edad. Por el contrario, en los municipios semirrurales y rurales del litoral gallego y cantábrico (grupo 5n), aparece el índice de aportación leve concentrando a una gran mayoría de los municipios en el 2002-2007, reduciéndose levemente en 2008-2011. Estos datos nos muestran la notable diferencia entre este ámbito territorial donde el turismo residencial, tan característico de las costas levantina y sur, es prácticamente inexistente, la presencia de inmigrantes menor y, por tanto, su aportación para incrementar el grupo de ancianos es substancialmente más reducida.

La contribución de los extranjeros al incremento del colectivo de ancianos en España es una variable que muestra disparidades en el tiempo y en el espacio. Cronológicamente es más acusada en la primera de las dos etapas analizadas (2002-2007), que ofrece valores sistemáticamente mayores en comparación con los resultados obtenidos en el período siguiente (2008-2011). Pero, sobre todo, ofrece grandes contrastes espaciales. Así, tomando los valores de contribución obtenidos para el conjunto de la etapa analizada, las áreas litorales mediterráneas e insulares (grupos 03 y 05) ofrecen los resultados más abultados, dato consistente con la localización de los principales destinos para migrantes por razón de ocio y recreación en nuestro país. Por su parte, las restantes agrupaciones, dominadas por migrantes laborales, realizan una contribución al crecimiento del número de mayores que se mantiene muy por debajo de la participación del colectivo de migrantes sobre el total de población.

Pero no sólo existen disparidades en la participación de los extranjeros sobre la variación del colectivo de ancianos. Del mismo modo, existen claras discrepancias intragrupos, reveladas por la cartografía, pero también si introducimos en las mediciones las disparidades de tamaño de los diferentes municipios. Al aplicar medias ponderadas encontramos algunas diferencias significativas respecto al indicador de contribución de extranjeros a la forma- 
ción del grupo de ancianos, si bien éstas son sólo apreciables a lo largo del período 2002-2007: en primer lugar, la contribución a la variación de las cohortes de mayor edad es significativamente menor a lo sugerido por las cifras sin ajustar, hecho posiblemente propiciado por los fuertes contrastes intragrupo en lo relativo a la talla municipal; en segundo lugar, en las agrupaciones donde la contribución de extranjeros es superior (agrupaciones 03 y 05), pero también en las áreas metropolitanas (agrupación 01) y las pequeñas ciudades del interior (agrupación 04), ocurre justo lo contrario, de manera que los valores ajustados son superiores a los datos sin ajustar, diferencia posiblemente atribuible a una clara tendencia de los ancianos extranjeros a concentrarse en un número relativamente reducido de municipios.

CORRELACIÓN ENTRE POBLACIÓN ANCIANA EXTRANJERA Y LAS PRINCIPALES NACIONALIDADES

En el cuadro 4 se representan los resultados de aplicar el coeficiente de correlación de Pearson, medida que permite establecer el grado de correlación entre los extranjeros ancianos residentes en cada municipio en España y los empadronados oriundos del Reino Unido, Rumanía, Ecuador y Marruecos. Como señalamos en el apartado 2 ambas variables han sido convertidas en logaritmos naturales.

Tomando la totalidad de los municipios españoles las cifras muestran claramente como, de una parte, la población británica sigue una distribución similar a la de los ancianos extranjeros, mientras que los otros tres orígenes muestran unos niveles de correlación bajos. A partir de niveles extremadamente significativos (p-valor del 0,000, reflejo de correlaciones significativas, al 0,01), el ajuste es muy bueno para los oriundos del Reino Unido (el índice es siempre superior a 0,800 ); mientras que las otras tres comunidades el coeficiente se mantiene en la banda de los 0,500 y 0,600, si bien con valores crecientes en el tiempo. Estas cifras sugieren que, razonablemente, podemos pensar en una conexión positiva entre envejecimiento y población originaria de las Islas Británicas, consistente con la literatura sobre turismo residencial que se suele centrar en este colectivo (Huete y Mantecón, 2011; Rodríguez Rodríguez, 2004). En cambio, se puede pensar en los demás colectivos como ajenos al envejecimiento, lo que resulta lógico dada la motivación laboral de sus movimientos migratorios y la escasa tradición inmigratoria del territorio español (significativo es el hecho de que la comunidad rumana, de constitución más reciente, tenga los valores de correlación 
CuAdro 4

ÍNDICE DE CORRELACIÓN DE PEARSON BILATERAL

\begin{tabular}{llrrr}
\hline \multirow{3}{*}{ Británicos } & \multicolumn{1}{c}{2002} & \multicolumn{1}{c}{2007} & \multicolumn{1}{c}{2011} \\
& Pearson & $0,826^{* *}$ & $0,804^{* *}$ & $0,828^{* *}$ \\
& Significación & 0,000 & 0,000 & 0,000 \\
& Casos & 1.861 & 2.385 & 2.800 \\
\hline \multirow{3}{*}{ Rumanos } & Pearson & s.d. & $0,486^{* *}$ & $0,533^{* *}$ \\
& Significación & s.d. & 0,000 & 0,000 \\
& Casos & s.d. & 2.910 & 3.716 \\
\hline \multirow{3}{*}{ Ecuatorianos } & Pearson & $0,510^{* *}$ & $0,604^{* *}$ & $0,623^{* *}$ \\
& Significación & 0,000 & 0,000 & 0,000 \\
& Casos & 1.592 & 2.277 & 2.585 \\
\hline \multirow{2}{*}{ Marroquíes } & Pearson & $0,525^{* *}$ & $0,569^{* *}$ & $0,597^{* *}$ \\
& Significación & 0,000 & 0,000 & 0,000 \\
& Casos & 1.953 & 2.741 & 3.302 \\
\hline
\end{tabular}

Fuente: Elaboración propia a partir de datos del Padrón Municipal de habitantes.

** Correlación significativa al nivel 0,01 (bilateral).

más bajos); aunque se detecta un suave incremento de los valores de correlación de estos colectivos según avanza el tiempo, no creemos que se pueda pensar en un incremento del envejecimiento real de estos colectivos (la reagrupación familiar opera, generalmente, en sentido opuesto) sino de un desplazamiento de estos inmigrantes hacia territorios con un fuerte peso de la denominada migración residencial (Dubón, Carretero y Serra, 2009; Rodríguez y Mora, 2009).

Las cifras representadas en la tabla anterior tienen una traducción más plástica en los gráficos de regresión (figura 3), en los que se representan las correlaciones observadas (en ordenadas se recoge el logaritmo natural correspondientes al montante municipal de cada colectivo nacional, en abscisas representamos el logaritmo natural de los extranjeros de más de 65 años) añadiendo la recta de ajuste óptimo entre ambas variables. En este caso, a fin de simplificar la exposición, nos limitamos a 2011, y de su observación se pueden extraer algunas conclusiones: 


\section{FIGURA 3}

AJUSTE ENTRE LA RECTA DE REGRESIÓN Y LOS PARES DE VALORES

OBSERVADOS EXPRESADOS MEDIANTE LOGARITMOS NATURALES

(POBLACIÓN ANCIANA EXTRANJERA - POBLACIÓN EXTRANJERA DE LAS PRINCIPALES NACIONALIDADES)
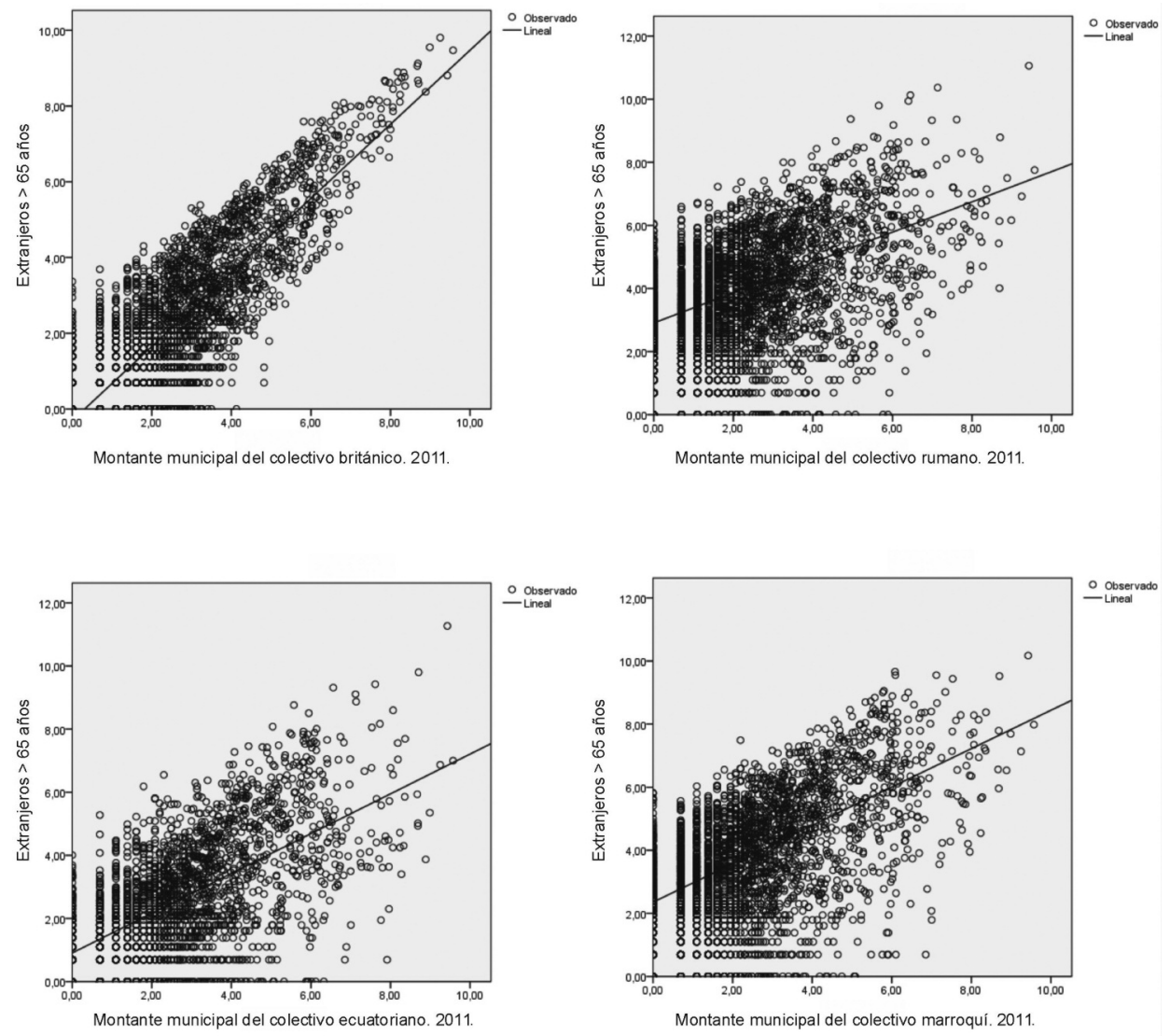

a) La nube de observaciones para el colectivo británico se ajusta mejor a la recta de regresión que los otros tres casos. Para los rumanos, ecuatorianos y marroquíes las irregularidades en relación a la recta se acrecientan extraordinariamente, hasta el punto de pensar que no existe una clara relación entre distribución municipal de estos tres colectivos y la de la población anciana extranjera. 
b) La aparente similitud entre los patrones gráficos de estas tres comunidades, que hacen pensar en que existe coincidencia geográfica en el asentamiento de unas y otras. Posiblemente sea la población ecuatoriana, tal y como sugiere el indicador, donde la nube de observaciones tiene un componente aleatorio menor.

c) La inclinación de las rectas de regresión para cada uno de los colectivos es un indicador adicional a los coeficientes de correlación de Pearson. Para los británicos dicha recta parte de un punto cercano al origen de abscisas y coordenadas, y posee una inclinación semejante a la recta que representaría una correlación perfecta (en este caso se trataría de una inclinación de $45^{\circ}$ ). En cambio, las restantes rectas muestran que el ajuste en las regresiones de cada una de ellas se aleja de una correlación perfecta, poseen una inclinación menor, de tal manera que a un incremento del número de nacionales de dichas comunidades le corresponde una variación correlativa de ancianos extranjeros menos que proporcional.

Lo comentado hasta el momento permite afirmar que existe una gradación en el nivel de envejecimiento de cada colectivo nacional de extranjeros: entre los británicos es elevado, posiblemente por encima del que corresponde a la población española; las otras tres comunidades son aún jóvenes (Ilisescu, 2009; Prada, 2009; Marcu, 2011), si bien los ecuatorianos posiblemente posean un grado de envejecimiento superior a rumanos y marroquíes (García y Palacios, 2009; Colectivo IOÉ, 2012), quienes aún se caracterizan por la escasez de ancianos entre ellos.

\section{CONCLUSIONES}

En el período contemplado en el artículo la inmigración ha contribuido a retrasar el envejecimiento de la población residente en España, si bien en los últimos años y debido a la fuerte crisis económica esa minoración del envejecimiento ha sido menor muy probablemente debido a la marcha de muchos inmigrantes buscando mejores perspectivas económicas en otros lugares. Ese rejuvenecimiento no ha sido territorialmente uniforme, sino que ha variado según la importancia de la recepción de inmigrantes y del dinamismo económico de las áreas receptoras. Para conocer como la inmigración ha afectado al grupo de ancianos y hacer patentes estas diferencias hemos acudido a un análisis a escala municipal de la de la contribución del colectivo de inmigrantes extranjeros al incremento de las cohortes por encima de 65 años de la población española para los períodos 2002-2007 y 2008-2011, agrupando estos territo- 
rios según criterios de homogeneidad geográfica, apareciendo las principales disparidades en tres contextos: aquellas áreas de inmigración de ancianos o de personas de elevada edad media que llegan buscando el sol del sur (litoral Mediterráneo y los archipiélagos canario y balear), donde éstos han supuesto una contribución patente y notable sobre el grupo de personas de mayor edad y también sobre el envejecimiento de la población total de los municipios en los que se asientan; aquellas otras donde la actividad económica ha tenido un dinamismo significativo, que han concentrado grandes contingentes de inmigrantes laborales jóvenes, donde han contribuido a suavizar las tasas de envejecimiento, sobre todo en los últimos cuatro años; y, finalmente, una parte sustancial del territorio, ajeno a los flujos migratorios por una atonía económica (y también demográfica) donde no ha habido una aportación relevante en uno u otro sentido. Pero no nos hemos limitado a considerar a los inmigrantes como un grupo uniforme, también nos hemos aproximado a la incidencia sobre el incremento del número de ancianos de los colectivos nacionales más destacados presentes en nuestro Estado. En la contribución al aumento de los ancianos, el grupo de foráneos británicos son los que poseen un mayor protagonismo, dada su condición de integrantes de flujos de turismo residencial. Por su parte, los marroquíes y ecuatorianos presentan un aporte menor (aunque creciente dada su ya larga tradición de asentamiento en España), y especialmente de rumanos, con unos flujos hacia España mucho más recientes.

Somos conscientes de que los indicadores y métodos estadísticos utilizados presentan algunas debilidades. Tal y como señalamos en el apartado dedicado a exponer la metodología, el indicador ideado para medir la contribución de los extranjeros a la variación del número de anciano ofrece resultados insatisfactorios en los casos de comparación de flujos de distinto signo aritmético, generalmente en municipios de escasa talla demográfica. Por otra parte, la medición de la correlación entre la distribución de nacionales de determinados países y la del colectivo total de ancianos ha venido lastrada por la ausencia de datos sobre estructura de edades para los distintos grupos nacionales, obligando a tomar con ciertas cautelas los resultados obtenidos.

En todo caso, nuestra intención, además del análisis realizado, es por un lado la de contribuir al debate, con múltiples aristas, sobre los efectos de la fuerte inmigración recibida en España a lo largo de la década de 2000 y que ha sido frenada en seco por la fuerte crisis económica que padece el país. En este sentido, la principal aportación de este trabajo es cuantificar con datos concretos muchas afirmaciones que se han hecho hasta el momento en la literatura científica sobre migraciones en España, observaciones apoyadas sólo en intuiciones fruto de la observación directa de casos muy concretos. 
De los datos más recientes recogidos parece intuirse algo novedoso en nuestro país: en los próximos años la contribución al incremento de los grupos etarios de la cúspide de la pirámide demográfica por parte de los foráneos será mayor, algo que ya se ha constatado en otros estados europeos en diferentes momentos (Triandafyllidou y Gropas, 2007; Parsons y Smeeding, 2006). La crisis económica ha supuesto un fuerte frenazo a la incorporación de nuevos inmigrantes, de manera que dada la juventud diferencial de los que estaban llegando, es esperable que se vaya produciendo un incremento de la edad media de los que permanezcan en España y consecuentemente participen de manera más destacada en el incremento el grupo de ancianos en un futuro más o menos cercano, con las repercusiones económicas evidentes que ello tendrá.

Fecha de recepción: 19 de diciembre de 2012.

Fecha de aceptación: 30 de mayo de 2013.

\section{BIBLIOGRAFÍA}

Aldrey Vázquez, J. A.; González Pérez, J. y Santos Solla, X. M. (2008): A inmigración estranxeira en Galicia. Identificación de comportamentos sociais e decisións territoriais a partir da opinión dos diferentes colectivos de inmigrantes. Santiago de Compostela, Secretaría Xeral de Emigración da Xunta de Galicia.

Antuñano Maruri, I.; Ochando Claramunt, C. y Soler Guillén, A. (2009): "Inmigración, mercado de trabajo y Seguridad Social: evidencia empírica española e implicaciones de política económica". Revista del Ministerio de Trabajo y Asuntos Sociales, 81, pp. 17-39.

Arango Vila-Belda, J. (2004): "Inmigración, cambio demográfico y social". Información Comercial Española, 815, pp. 31-44.

Benson, M. y O'Reilly, K. (2009): Lifestyle migration. Expectations, aspirations, experiencies. Ashgate, Cornwall, Publishing Limited.

Cabré, A. y Domingo, A. (2007): "Demografia i immigració, 1991-2005”, en Annuari. Economía catalana: reptes de futur. Barcelona, BBVA/Generalitat de Catalunya, pp. 105-126.

Carvajal, C. y Navarro, E. (2011): "Propuestas metodológicas para la cuantificación de los residentes no empadronados. Aplicación en la costa malagueña", en I. Pujadas, et al. (eds.): Población y Espacios urbanos. Barcelona, Departament de Geografia Humana de la UB y Grupo de Población de la AGE, pp. 541-555.

Casado Díaz, Ma . A. y Rodríguez Rodríguez, V. (2002): "La migración internacional de retirados en España: limitaciones de las fuentes de información". Estudios Geográficos, 63/248-249, pp. 533-558.

Castro Martín, T. (2010): “¿Puede la inmigración frenar el envejecimiento de la población española?”, ARI, 40, http://www.realinstitutoelcano.org/wps/portal/rielcano/ 
contenido?WCM_GLOBAL_CONTEXT=/elcano/elcano_es/zonas_es/de mografia+ y+poblacion/ari40-2010 (Fecha de consulta: 30/10/2014).

Colectivo IOÉ (2012): Crisis e inmigración marroquí en España, 2007-2011. http://www.colectivoioe.org/uploads/16ed2b9a5f0868dc55be62fa17d667ca48a979 80.pdf (Fecha de consulta 30/10/2014).

Conde Ruiz, J. I.; Jimeno Serrano, J. F. y Valera Blanes, G. (2006): Inmigración y pensiones: ¿Qué sabemos? Bilbao, Fundación BBVA.

Conde Ruiz, J. I.; García, J. R. y Navarro, Ma (2008): "Inmigración y crecimiento regional en España". Colección Estudios Económicos, 09-08, Madrid, FEDEA. www.estudios.lacaixa.es

Copete Fernández, J. Ma y Sempere Souvannavong, J. D. (2009): “Crevi-Mellal, El territorio marroquí de Crevillent (Alicante)", en C. Montoro et al. (eds.): La inmigración internacional: motor de cambios sociodemográficos y territoriales. Pamplona, Eunsa, pp. 133-137.

De Castro, M. A. (2004): "Fuentes estadísticas sobre la inmigración". Economistas, 99, pp. 6-14.

Dehesa, G. de la (2000): Comprender la inmigración. Madrid, Alianza Editorial.

Delgado, M. y Zamora, F. (2004): "Españoles y extranjeros: su aportación a la fecundidad en España". Economistas, 99, pp. 88-97.

Devolder, D.; Gil, F. y Forte, P., (2009): "Estimación del grado de error en el registro de la población extranjera en España: un enfoque comparativo", en C. Montoro, et al. (eds): La inmigración internacional: motor de cambios sociodemográficos y territoriales. Pamplona, Eunsa, pp. 163-172.

Dubón, M. L. et al. (2009): "Los cambios migratorios recientes en las Illes Balears y su repercusión en la sociedad insular", en C. Montoro, et al. (eds): La inmigración internacional: motor de cambios sociodemográficos y territoriales. Pamplona, Eunsa, pp. 181-191.

García, M. T. y Palacios, M. T., (2009): "La evolución de la población ecuatoriana en la Comunidad de Madrid: aspectos sociales, económicos, políticos y culturales", en C. Montoro, et al. (eds): La inmigración internacional: motor de cambios sociodemográficos y territoriales. Pamplona, Eunsa, pp. 199-204.

García Ballesteros, A. y Sanz Berzal, B. (coords.) (2002): Atlas de la Comunidad de Madrid en el umbral del siglo XXI. Madrid, Comunidad de Madrid/Universidad Complutense de Madrid.

García Casado, Mª T. y Palacios Estremera, Mª T. (2009): "La evolución de la población ecuatoriana en la Comunidad de Madrid: aspectos sociales, políticos y culturales", en C. Montoro, et al. (eds): La inmigración internacional: motor de cambios sociodemográficos y territoriales. Pamplona, Eunsa, pp. 199-204.

Garrido, L. (2004): "Para cuantificar a los extranjeros". Economistas, 99, pp. 28-37.

Garrido Medina, L. (2005): "La inmigración en España”, en J. J. González, y M. Requena, (eds.): Tres décadas de cambios sociales en España. Madrid, Alianza Editorial, pp. 127-164. 
Huete Nieves, R. y Mantecón, A. (2011): "Más allá del turismo: movilidad residencial europea y nuevos núcleos urbanos". Boletín de la Asociación de Geógrafos Españoles, 56, pp. 111-128.

Ilisescu, I. G. (2009): "Las causas y consecuencias de las migraciones internacionales de los rumanos", en C. Montoro, et al. (eds.): La inmigración internacional: motor de cambios sociodemográficos y territoriales. Pamplona, Eunsa, pp. 247-253.

Janoschka, M. y Haas, H. (2013): Contested spatialities, lifestyle migration and residential tourism. Londres, Routledge.

Jansà, J. M. (2006): "Inmigración y envejecimiento, nuevos retos en salud pública". Gaceta Saniteria, 20 (suplemento 1), pp. 10-14.

Jiménez-Ridruejo Ayuso, Z. (2008): "Envejecimiento e inmigración: consecuencias sobre la sostenibilidad del sistema de pensiones en España”. Revista del Ministerio de Trabajo y Asuntos Sociales, 74, pp. 359-377.

Jiménez-Ridruejo Ayuso, Z. y Bordondo Arribas, C. (2009): "Inmigración y Seguridad Social: perspectivas económicas y demográficas". Revista del Ministerio de Trabajo y Asuntos Sociales, $\mathrm{n}^{\mathrm{o}}$ extra 1, pp. 109-127.

López, A.; Castellano, L. A.; Díez, C. y Escalona, A. I. (2002): "Carácter y localización de las nuevas empresas en el área metropolitana de Zaragoza (1997-2000)". Ería, 57, pp. 71-78.

López de Lera, D. (2006): "Panorama de la inmigración", en A. Izquierdo Escribano, (dir.): Demografía de los extranjeros. Incidencia en el crecimiento de la población. Bilbao, Fundación BBVA, pp. 17-71.

López Trigal, L. (2010): "Complejidad y perfil de las migraciones ibéricas, una aproximación geográfica”. Polígonos. Revista de Geografía, 20, pp. 197-204.

Marcu, S. (2011): "La Inmigración rumana en la Comunidad de Madrid después de 20 años: circularidad y retorno", en I. Pujadas, et al. (eds.): Población y Espacios urbanos. Barcelona, Departament de Geografia Humana de la UB y Grupo de Población de la AGE, pp. 737-751.

Martínez Buján, R. (2005): "El cuidado de ancianos. Un vínculo entre la inmigración y el envejecimiento". Panorama Social, 2, pp. 86-97.

Martínez Buján, R. y Villares Varela, M. (2006): "Contextos de llegada e instalación", en A. Izquierdo Escribano, (dir.): Demografía de los extranjeros. Incidencia en el crecimiento de la población. Bilbao, Fundación BBVA, pp. 137-236.

Nel.lo, O. (2007): "La tercera fase del proceso de metropolitanización en España", en: Los procesos urbanos postfordistas. Palma de Mallorca, Universitat de les Illes Balears, pp. 19-31.

Oso Casas, L. (2006): "Pautas demográficas de los extranjeros", en A. Izquierdo Escribano, (dir.): Demografía de los extranjeros. Incidencia en el crecimiento de la población. Bilbao, Fundación BBVA, pp. 73-136.

Pajares Alonso, M. (2009): "Comunidades Inmigradas de la Europa del Este. El caso del colectivo rumano en España”. Revista CIDOB d AfersInternacionals, 84, pp. 65-79. 
Parsons, C. A. y Smeeding, T. M. (2006): Immigration and the transformation of Europe. Cambridge, University Press,

Prada, J. (2009): "La relevancia de la inmigración rumana en Castilla-La Mancha: el impacto de las nuevas dinámicas migratorias en las agrociudades manchegas", en C. Montoro, et al. (eds.): La inmigración internacional: motor de cambios sociodemográficos y territoriales, Pamplona, Eunsa, pp. 181-191.

Recaño, J. y Domingo, A. (2005): "Factores sociodemográficos y territoriales de la inmigración irregular en España", comunicación al XXV Congreso Internacional de la Población 2005. Tours, Francia, (Documentación inédita del congreso).

Rodríguez, M. J. y Mora, R. (2009): "La transición de los modelos migratorios en escenarios turísticos. El caso del litoral alicantino", en C. Montoro, et al. (eds): La inmigración internacional: motor de cambios sociodemográficos y territoriales. Pamplona, Eunsa, pp. 361-367.

Rodríguez Rodríguez, V. (2004): "Turismo residencial y migración de jubilados", en: Las nuevas formas de turismo. Almería, Cajamar, pp. 233-253.

Rodríguez Rodríguez, V. (2012): Inmigración y cuidados a personas mayores en la Comunidad de Madrid. Madrid, Fundación BBVA.

Triandafyllidou, A. y Gropas, R. (2007): European Immigration. A Sourcebook. Limited, Cornwall, Ashgate Publishing.

United Nations (2001): Replacements migration: it is a solution to declining an ageing populations? http://www.un.org/esa/population/publications/migration/migrtions. htm. (Fecha de consulta: 30/10/2014).

Valero Escandell, J. R. (2009): "La España receptora: algunas transformaciones socioterritoriales en un período de inmigración intensa", en C. Montoro, et al. (eds.): La inmigración internacional: motor de cambios sociodemográficos y territoriales. Pamplona, Eunsa, pp. 15-36.

Villena Rodríguez, Ma y Gómez García, F. (2006): "Demografía, mercado de trabajo y política de inmigración en España". Revista del Ministerio de Trabajo y Asuntos Sociales, 61, pp. 15-40.

\section{RESUMEN}

La literatura científica sobre el fenómeno inmigratorio en la España de los últimos quince años ha sido abundante en tanto y cuanto a su carácter masivo. Sin embargo, muy poco o nada se ha profundizado en la repercusión de la inmigración sobre la población anciana. En este artículo se aborda este tema, desde una perspectiva que se aproxima a la escala municipal y a determinados colectivos de inmigrantes que, aunque diferentes en cuanto a su estructura interna y motivaciones de llegada, se cuentan entre los que han aportado mayores contingentes: británicos, marroquíes, ecuatorianos y rumanos. Se divide el análisis en dos períodos diferentes, 2002-2007, en el que el crecimiento económico y la demanda de mano de obra foránea eran elevadas, y 2008-2011, en el que la crisis dejó sentir ya de manera rotunda su incidencia. Los re- 
sultados muestran una aportación leve al crecimiento de la población de mayor edad, aunque con matices.

Palabras Clave: inmigración; migración laboral; migración por estilo de vida envejecimiento demográfico; España.

\begin{abstract}
Academic literature concerning immigration in Spain over the last fifteen years has been extensive in respect of the fact that it has been a mass phenomenon. However, little or no in-depth attention has been paid to the repercussions of immigration on the demographic aging of the population. The present paper addresses this topic from a perspective that focuses primarily on municipal units. It investigates various groups of immigrants that, although differing in regard to their internal structure and motivations for coming to Spain, are among those that have supplied the largest contingents: British, Moroccan, Ecuadorian and Romanian citizens. The analysis covers two different periods. The first is 2002 to 2007, when economic growth and the demand for foreign labour were both high. The second is 2008 to 2011, when the crisis made itself felt in a particularly forceful way. The results show a slight contribution to demographic ageing, although with variations.
\end{abstract}

KEY WORDS: immigration; labour migration; migration by life-style; demographic aging contribution; Spain.

\title{
RÉSUMÉ
}

La littérature scientifique sur le phénomène migratoire de ces quinze dernières années en Espagne est abondante, à la mesure de son caractère massif. Cependant, très peu d'études, voire aucune, n'ont été faites sur l'influence de l'immigration sur la population du troisième âge. Cet article aborde ce sujet d'un point de vue proche à l'échelle locale et à certains collectifs d'immigrés qui, bien que différents quant à leur structure interne et leurs motivations d'arrivée, figurent parmi ceux qui ont apporté les plus grands contingents : Britanniques, Marocains, Équatoriens et Roumains. Lanalyse est divisée en deux périodes différentes : 2002-2007, pendant laquelle la croissance économique et la demande de main d'œuvre étrangère étaient élevées; et 2008-2011, pendant laquelle les effets de la crise se faisaient déjà sentir de manière évidente. Les résultats montrent un apport léger à la croissance de la population du troisième âge, bien qu'avec quelques nuances.

MotS CLÉs: immigration; migration et travail; migration par style de vie; vieillissement démographique; Espagne. 